\title{
Sociolinguistic Variation in Athenian Suburban Speech
}

\author{
Irene Theodoropoulou \\ Qatar University \\ irene.theodoropoulou@qu.edu.qa
}

\begin{abstract}
This article focuses on the description and interpretation of the social meaning of sociolinguistic variation in Athenian suburban speech. A descriptive statistical and a Varbrul analysis of the syntactic variable Verb and presence or absence of Prepositional Phrase $(V+/-P P)$, as it is used by native northern and western suburbanites of Athens, suggests that primarily the area (northern and western suburbia) and, to a lesser extent, the sex of the speakers are statistically significant macro social factors constraining variation. In an effort to tease out the social meaning of the variation, a further analysis of some micro factors within each area, including the group of speakers, the topic, and the stance towards the rivalry between the aforementioned suburban areas, suggests that variation in both areas is interactionally constrained, but in the northern area it tends to be more friendship group-constrained, while in the western area it is more education-constrained. In light of these findings, the sociolinguistic implications of the study translate into the analytical need to account for the relationship between interactional and social factors in the description of variable grammars.
\end{abstract}

Keywords

sociolinguistic variation; Athenian Greek; stance; social class; Varbrul; semi-structured conversation; friendship group; suburbs

\section{Introduction}

The recent (and still ongoing) social unrest in Athens, the capital of Greece, resulting primarily from the austerity measures that the Greek government has adopted in order to tackle the harsh financial situation the country has been facing for a long time, has revived an interdisciplinary interest in the social geographical mosaic of the contemporary Athenian society. It is beyond the scope of this paper to provide the reader with a robust sociological description of each and every one of the social classes in contemporary Athens, which can be found elsewhere. ${ }^{1}$ Instead, the focus of this paper is at once more modest

1) See, for example, the studies by Emmanuel $(2004,2007)$ and Maloutas and Karadimitriou (2001). 
and more concrete: it aims to identify, describe and interpret sociolinguistic variation among the social classes that is pertinent to the western ( $\delta v \tau i x \alpha$ $\pi \rho 0-$

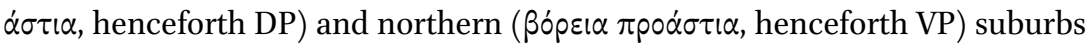
of Athens.

These two areas have been stereotypically treated as boasting different social classes, between which there seems to be a class rivalry; on the one hand, the leafy northern suburbs are seen as consisting of primarily well-to-do and/or educated people, while the poorer western suburbs are seen as playing host to less well-off people and/or people of vulgar origin, who are uneducated and/or uncultivated. Evidence of this class rivalry is found in Modern Greek popular culture, such as in Modern Greek hip-hop or on TV (for a detailed discussion, see Theodoropoulou 2010b, 2011). These popular culture representations coupled with my informal observations in suburbanites' discourse on these rivalries are the impetus for the present study. More specifically, by using data from actual (and not fictional, as is the case in popular culture) participants, I aim to describe the sociolinguistic variation in these two areas and tease out and interpret its social meaning.

The paper is structured as follows: after providing a detailed account of how social class is conceptualized in this study and what kinds of social classes are included in these two areas, I discuss my methodology for data collection and analysis and give a description of my data. I then move to report my findings and provide an analytical discussion thereof. Finally, I conclude by discussing the study's sociolinguistic implications.

\section{Social Class Landscape in Contemporary Suburban Athens}

Social class has been of great interest in the social sciences in general, particularly in sociology, where it is often treated as the cornerstone of the stratification of society. In Marxism, social class is located at the level of production and is identified with the means of production and the position of human beings with respect to the social system of production, while in the Weberian conception, social class is located at the level of market, and classes are people with similar command over economic resources and similar lifestyle choices (Sørensen 2001: 135-137; Macy 2001: 363-364).

In the geographical and sociological literature on urban modern Greece, it has been found that class hierarchy becomes evident through the tendency of households sharing the same socioeconomic background to concentrate in areas whose property values, types of housing (e.g., mansions or spacious apartments vs. small-scale flats) and general distribution of space (e.g., gardens, parks, wide as opposed to narrow streets) correspond to their lifestyle and their consumerist behaviour (Emmanuel 2008: 62). In other words, according to the 
area they live in and the type of property they live in, people can be located within the social class hierarchy, on the grounds that the area and the type of property reflects their lifestyle practices and, accordingly, the financial state of affairs required to afford such a lifestyle. Conversely, households tend to avoid acquiring, i.e. buying or renting, property in areas which diverge from the aforementioned area and property values, regardless of whether these values are higher or lower, better or worse. In light of this Weberian take, in the northern and southern suburbs of Athens, where the values per square meter for new properties are high (see map 1), the social classes that tend to live there are usually upper- and upper-middle-class people. The most expensive northern suburbs include areas such as Kifisia, Ekali, Nea Erythraia, Palaio Psychiko, according to map 1 (the red shaded areas with the highest values, i.e. 450,000 drachmas per square meter, according to the 1991 Census). On the contrary, in downtown Athens, and especially in the western suburbs of Athens, such as Peristeri, Liosia, and Magoula, to name just a few, the property values are very low (areas in navy blue on map 1), a fact that makes these areas particularly appealing to lower-middle-class and working-class people.

The western suburbs of Athens are associated with the dense, social networks of the traditional working class families who lived in this part of the prefecture of Attica primarily because of the existence of an industrial zone comprising factories and family-scale businesses (Triantafyllopoulou 2006).

In light of these areal differences in terms of social class stratification, we expect to find sociolinguistic variation as well. In variationist sociolinguistics, social class has been dealt with as a major factor in linguistic variation in diverse contexts all over the world (for an overview, see Labov 2006: 380-403). Nonetheless, it has been argued that social class has been used in an uncritically deterministic way, which in turn has made it substituting for analysis (Meyerhoff 2011: 192). As a result of this tendency, it has been observed that research on more local identities has largely eclipsed the study of social class (ibid.) In this particular study, it is argued that social class is a useful point of entry into the analysis of sociolinguistic variation between VP and DP and in people's perceptions (Theodoropoulou 2010a), but as the analysis shows below, the labels comprise other dimensions as well, including interactional ones.

Despite its importance as a research site for the study of on-going social, as has become evident, and, henceforth, sociolinguistic as well, changes in Greece, Athens has not so far been the subject of extensive (variationist) sociolinguistic analysis. Notable exceptions to this are a large-scale variationist study by Mikros (1997) and a smaller-scale study by Arvaniti and Joseph (2000), all of which, nonetheless, focus on phonological variation (the realization of prenasalized sounds [mb], [nd], [ng]). The analysis reported here is to my knowledge the first sociolinguistic account of syntactic variation in Athens. There are 


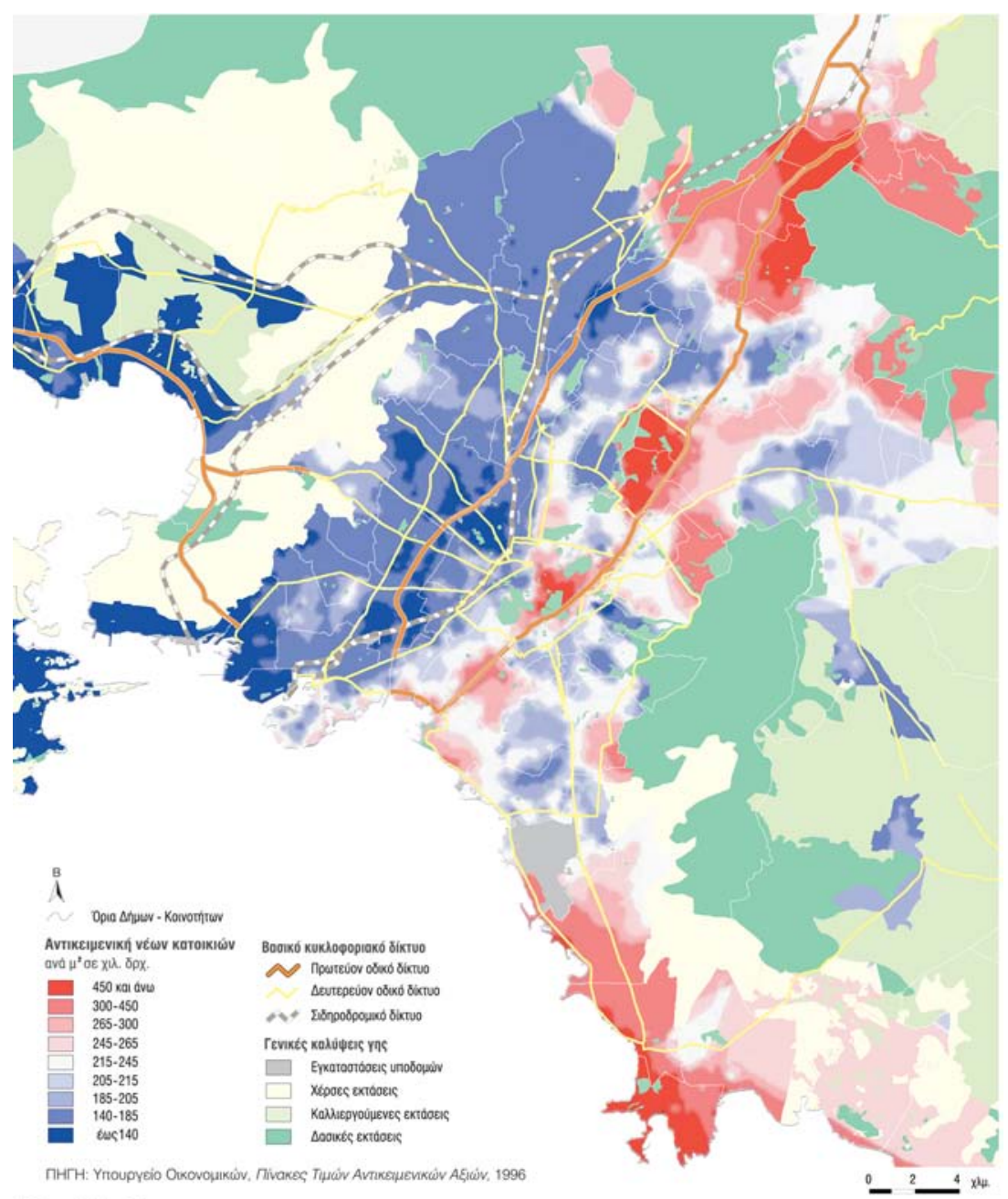

Map 1. Map of the prefecture of Attica and the values for new property according to the area (taken from Maloutas 2002: 54) Areas shaded in dark red (northern suburbs) have the highest values, i.e. 450,000 drachmas per square meter, according to the 1991 Census. $^{2}$ Areas shaded in dark blue (western suburbs) have the lowest values, i.e. up to 140,000 drachmas per square meter, according to the 1991 Census. $^{3}$

2) This state of affairs has not changed since then. After the advent of Euro on the ist of January 2001, the property values increased significantly compared to the previous years, when the currency was the drachma, but the pattern of having high property values in the aforementioned 
no earlier sociolinguistic studies on which I can draw. Therefore, I begin by briefly describing the variable and the internal linguistic and external social and interactional factors that I, as a native speaker, have identified as potential constraints in syntactic variation in Athenian suburban Greek, to set the scene for my own analysis.

\section{The Variable}

Aligning with some of the most influential variationist sociolinguistic studies, I treat (socio)linguistic variable as 'a set of alternative ways of saying the same thing, although the alternatives will have social significance' (Fasold 1990: 223-224). The variable must also correlate with patterns of social and/or linguistic phenomena (Tagliamonte 2006: 76 ), and, in the case of conversations, from which my data stem, also interactional phenomena. Moreover, it must have qualities of system and distribution, even if these are only revealed by the analysis (ibid.)

The present study focuses on one syntactic variable, which is the movement verb $(\mathrm{V})+$ / - PP, translated into the presence or absence of a Prepositional Phrase (henceforth PP) following one of the following movement verbs (henceforth V): $\pi \eta \gamma \alpha i v \omega$ ('I go') or $\pi \alpha \omega$ ('I go', but more informal than $\pi \eta \gamma \alpha i v \omega$; also used as the simple future of $\pi \eta \gamma \alpha i v \omega: \theta \alpha \pi \alpha$ ' ${ }^{\prime}{ }^{\prime}$ I will go'), and $\varepsilon p \chi o \mu \alpha$ ('I come'). The aforementioned three verbs have the same semantics but different pragmatic meanings regarding their relationship with distance; more specifically, the way they express spatial deixis, namely the relationship between the relative space of people and things vis-à-vis the speaker (Cairns 1991: 19), is different: $\pi \eta \gamma \alpha i$ $v \omega$ indexes that the speaker is not found at the point of his/her departure and $\pi \dot{\alpha} \omega$ that the speaker is at the point of his/her departure. On the contrary, the verb ह́pхo $\mu \alpha$ เ indexes the point of arrival, which is to be found close to the hearer (Canakis 2007:194). In addition, regarding the distinction between $\pi \eta \gamma \alpha i v \omega$ and $\pi \dot{\alpha} \omega$, even though they share exactly the same semantics, as we saw immediately above, they are different in terms of their formality: $\pi \eta \gamma \alpha i v \omega$ is more formal than $\pi \dot{\alpha} \omega$.

northern (and southern, but these are beyond the scope of this paper) suburbs has remained the same since then. For a relatively recent (i.e. 2007) account of property values, see the following links: http://www.alfamesitiki.gr/NOMARXIAKO\%20ATHINON.pdf (for the leafy areas in downtown Athens and northern suburbs thereof, accessed on 10/9/2011), and http://archive.in.gr/ akinita/pdf/4_NOMARXIAKH\%2oAYTODIOIKISH\%2oDYTIKHS\%2oATTIKHS.pdf (for the poorer areas in downtown Athens and western suburbs thereof, accessed on 16/4/2013).

3) Areas, such as the posh areas of Syntagma and Kolonaki or the area surrounding Lycabettus Hill and the areas surrounding the Hilton hotel, are excluded, because the value of property in these is high. 
Notwithstanding these differences, all three express movement towards a specific direction and to a destination (which can be closer to the speaker or closer to the addressee, as we saw) and all three can take as their complement the prepositional phrase $\sigma \varepsilon$ (to). It is exactly on the basis of these shared functional features that these three verbs are clustered together as the movement Verb -/+ Prepositional Phrase. In the Varbrul analysis (see methodology below), I coded my tokens for formality ( $\pi \eta \gamma \alpha i v \omega)$ vs. informality $(\pi \dot{\alpha} \omega)$, but these two factors have not been found to be statistically significant. Furthermore, the simultaneous treatment of all these verbs as equivalent in terms of their function is that, when taken together, they can yield many tokens of the variable $\mathrm{V}$ +/- PP, which is one of the basic rules of investigating sociolinguistic variation (Aguilar-Sánchez 2009).

The reasons why this specific variable has been selected as the focus of the study are three: a) as a native speaker of Athenian Greek, I hear some variation between people from the VP and the DP areas, hence I am interested in testing how this variable varies and what the social meaning of its variation is; $b$ ) this is a variable which occurs frequently in my conversational data sets; and c) the social meanings underpinning it are iconic of the respective speech styles under investigation. This last observation is based on my informal observations and discussions I have had with people from these two areas, and especially with some of the people from the VP (some of them belong to my participants, but some others do not), who tend to comment in a negative way on the lack of the prepositional phrase on behalf of DP people. In this sense, the lack of the prepositional phrase could be considered to fall somewhere between a stereotype and a marker, in the Labovian (1971) terminology, namely it is a variable that is limitedly recognized by some lay VP people as part of the stigmatized DP people's way of speaking (bringing it close to being a stereotype), but, on the other hand its use is not subject to wide metapragmatic discussion (bringing it closer to being a marker).

Interestingly enough, as a stylistic feature the omission of the PP is a stereotype indexing youth slang, and this is evident through its sociolectal performance in Greek popular culture. More specifically, the catch-phrase pame plateia? (= 'are we going [to] square?') was established as a benchmark of youth language through its extensive use by Jimmis, a cool young Kolonaki person, impersonated by the popular actor Lakis Lazopoulos in his popular show Deka Mikroi Mitsoi (cf. Psaltou-Joycey and Valiouli 1995). Because of this connotation, it is treated as the nonstandard variant. It is not clear, however, whether this coinage was the actual source of all subsequent preposition (se)-dropping since then or whether it reflected the preposition-dropping that was going on in actual speech. A historical account of the phenomenon is beyond the scope of this paper. At any rate, the phrase, which contains the verb and the presence 
of the complete Prepositional Phrase (e.g., pao stin plateia 'I go to the square') is the standard variant, meaning here the norm which represents an intersection of carefulness, education and social status (cf. Meyerhoff 2011: 18).

Among the most frequently used prepositions in Modern Greek is the preposition $\sigma \varepsilon$ (henceforth $s e=$ 'in, on, at, to'). This preposition, combined with the neuter article to, forms the combination sg sto/pl sta (meaning 'in the', 'on the', 'to the', 'at the'). Similarly, the same preposition combines with certain forms of the masculine and feminine articles, like ton, ti(n), tou, tis, and it means the same thing. The combination of the two is identified with the Prepositional Phrase (PP). The latter is defined by the occurrence of an element, the preposition $s e$, which can be identified by its ability to govern a case-marked nominal argument (the 'object' of the preposition) and its inability to show any inflectional markers itself (Joseph and Philippaki-Warburton 1987: 45).

In my collecting the tokens to be included in the Varbrul analysis (see below), I adhered to the principle of accountability (Wolfram 1993, cited in Tagliamonte 2011: 9), namely I accounted for contexts where the linguistic variable occurred as well as the contexts where it could have occurred but did not. The rationale behind this principle is that as analysts we cannot gain access to how a variant functions in a grammar without considering it in the context of the subsystem of which it is a part. Hence, each use of the variant under investigation can be reported as a proportion of the total number of relevant constructions, i.e. the total number of times the function (i.e. the same meaning) occurred in the data.

I analyzed the speech of the sample of my 48 participants (24 from the area of Peristeri and 24 from the area of Kifisia). Overall, in my corpus there are 13,608 tokens of the $\mathrm{V}+/-\mathrm{PP}$ variable. Out of these, $76 \%$ of the $\mathrm{V}+/-\mathrm{PP}$ tokens $(\mathrm{N}=$ $10,342 / 13,608$ ) have been included in the Varbrul analysis (see below); this $76 \%$ of the tokens includes only cases where the subject of the verb is either omitted, or immediately precedes or follows the verb.

Examples are provided below:

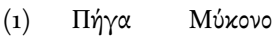

went.1sg. Mykonos.acc

'I went to Mykonos'-EXAMPLE OF OMISSION OF THE SUBJECT

(Giorgos, VP-M-26, 26/2/2007)

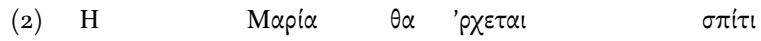

DEF.ART.fem Maria.nom PRT FUT.CONT.come.3sg home.acc

'Maria will be coming home'-EXAMPLE OF THE SUBJECT IMMEDIATELY PRECEDING THE VERB

(Kynthia, VP-F-25, 1/8/2008)

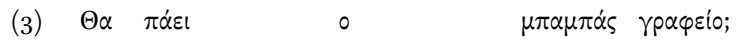

PRT FUT.SIM. go.3sg DEF.ART.masc dad.nom office.acc

'Is dad going the office?'-EXAMPLE OF THE SUBJECT IMMEDIATELY FOLLOWING THE VERB

(Kostas, DP-M-25, 4/9/2007) 
Occurrences, in which the verb $\pi \eta \gamma \alpha i v \omega$ and more often than not $\pi \dot{\alpha} \omega$ are used in slang with the meaning 'I fancy', have not been included in the Varbrul analysis, because they are categorical, that is to say they do not govern prepositional phrases, but their predicate always consists of an object of the verb in Accusative. Examples, like the one found in (4), have therefore not been included in the Varbrul analysis:

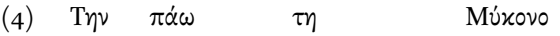
her.cl S.PR. go.1sg DEF.ART.fem. Mykonos.acc
'I fancy Mykonos'

(Plato, VP-M-25, 2/1/2008)

In this example, even though Mykonos is a place, given that it is governed by the verb $\pi \dot{\alpha} \omega$ in its slang function (meaning: 'I fancy'), it functions as the object of the verb, and as such it cannot be expressed in a prepositional phrase. If this were the case, namely if (4) had the form of (5):

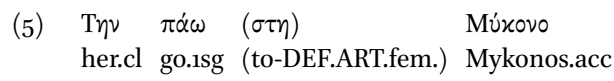

then the meaning would be totally different: 'I take her (to) Mykonos'. The $24 \%$ of the tokens that were not included in the Varbrul anaysis are either of the type of examples found in (4)-(5) or they are incomplete/unfinished sentences with the use of $\pi \eta \gamma \alpha i v \omega / \pi \alpha \omega / \varepsilon ́ p x o \mu \alpha$.

Having provided a description of the variable tested, I now to turn to a description of my methodology and data.

\section{Methodology and Data}

In order to investigate sociolinguistic variation in Athenian suburban speech, I used a combination of descriptive statistics and Varbrul analysis. Varbrul is a computer program that does statistical analysis of linguistic variables. It assumes that there is only one thing we investigate, the dependent variable, and that other observed factors can be related to it; the latter are called independent variables. The independent variables, features of the linguistic or extralinguistic context which impinge on the choice of one variant over the other, are the factors or factor groups (Tagliamonte 2006: 131). Through a multivariate analysis, we obtain factor weights, which are values anywhere from o to 1 (ibid. 145). When a factor weight is closer to 1 , it is interpreted as favoring the application value, while if it is closer to 0 , it is interpreted as disfavoring the application value.

My fieldwork yielded a corpus of around 14 hours of recorded semi-structured conversations, each recording ranging in length from about 45 minutes 
to 3 hours. This amounts to over 55,650 words, which have been broadly transcribed. All of the participant sound recordings, without me, the fieldworker, present, were made on a digital sound recorder (SONY ICDPX 312), and they took place between January 2007-December 2008 in various places that participants chose, including their houses, offices, cars, and (usually quiet) cafeterias. They were made after an initial observation period (Theodoropoulou 2010c).

Each token from the recordings was coded for a number of internal, i.e. linguistic, interactional and social constraints. I discuss here only the social and interactional factors which have been found to be significant: area, educational background, sex, group of speakers, topic of discussion, and stance towards the VP-DP rivalry.

\subsection{Area}

The aim of the project was to obtain a selection of speakers aged $25-35$ years, all of whom had been born and raised in the two areas studied. I wanted the speakers to reflect the social class makeup of the local population. Social class is notoriously difficult to define, and I assumed that although it may be highly salient within and between some friendship groups, for others it may be largely irrelevant. Thus I was less interested in the effect of social class per se than in using it as a broad social variable to ensure that my sample reflected the multiculturalism of the local area, and as a potential indication of the sociolinguistic variation that is characteristic of (suburban) Athenian Greek. In light of this, my usage has something in common with the way that speaker's sex is often used in variationist research, as a methodological, exploratory social variable. The variable is purposely broad and unrefined, as this allows it to be easily taken into account at the data collection stage (Milroy and Milroy 1997:53). However, by including it in my analysis I did not wish to impose my own classification on the speakers. Each individual was therefore asked to give a self-definition of 'where they belong' in terms of their own identity, and these are the definitions I use for the social class groups (cf. Cheshire and Fox's (2009) study).

The DP sample consists of 24 adolescent speakers, 12 male and 12 female. All of them have a 'Peristeri sociodemographic background' in that at least one previous generation of their families has relatively local roots. I term this group of speakers 'Peristeriotes' (= Peristeri people), following their unanimous preference for this label.

The VP sample consists of 24 adolescent speakers, 12 male and 12 female, predominantly from Kifisia also reflecting the local population. Out of these 24 speakers, 18 have a Kifisia sociodemographic background, in the sense that their parents have been living in Kifisia for almost 40 years, so these 18 were born and 
raised in the area. However, the remaining 6 are people who were born elsewhere (usually in downtown Athens or in the western suburbs of Athens) but moved into Kifisia during their early childhood and/or early adolescence due to their parents' significant improvement of their socioeconomic status. With the exception of two, who prefer the label 'Kifisiotis/-issa (female)', the rest of the 22 participants have adopted the label 'VP people/inhabitants' ( $x$ d to xo $\beta 0-$

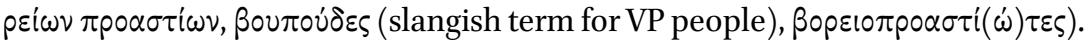
The variation in social meanings indexed by these different labels is beyond the scope of this paper.

\subsection{Educational Background}

The basic criterion relevant to my participants' educational background is whether they hold university degrees or not (this factor has been labeled 'education level'). Out of the 24 participants from Peristeri, there are 12, who hold university degrees ( 5 hold Masters and one holds a PhD as well), and 12 do not (i.e. the highest degree they have is their graduation title (apolytirio) from high school). Another factor that has been taken into consideration is the 'type of secondary education', namely whether the participants have graduated from state or private schools. Regarding the participants from Peristeri, 6 of them have graduated from state schools in the area, while the other six have graduated from two private schools also to be found in the wider area of western Attica. Regarding the VP participants, 12 of them hold graduation titles from high school and they are university and/or college drop-outs, while 12 of them hold BAs, out of whom 8 hold Masters degrees and 3 hold PhDs. A common pattern regarding the participants from Kifisia is that 8 of them have graduated from private schools found primarily in Palaio Psychiko, Agia Paraskevi and Kifisia (three northern suburbs of Athens), while the other three have graduated from state schools in Kifisia. The graduates from private schools all hold Masters degrees from prestigious universities in the UK and in the US, while the ones having graduating from state schools hold BAs and Masters from Greek universities. In light of this distribution, the VP group can be seen as more educated compared to the Peristeriotes group.

\subsection{Sex}

Aligning with major variationist studies, which have used sex as an independent variable (for a overview of such studies, see Cheshire 2002), both my samples from the two areas are symmetrical in terms of their sex representation: they consist of 12 males and 12 females each. 


\subsection{Group of Speakers}

There are 8 groups of participants ( 4 from the VP and 4 from the DP) in the study, consisting of 3 people each. So for each area, there were 8 recordings (some groups were single sex some others were mixed). The criterion for forming these 3-people groups was the participants and their friendship pairs, which led to small self-selected groups. All of these groups were asked to self-categorize, i.e. to give a label to their group, which indexes their relationship with their area (for a discussion, see the Varbrul analysis of the VP participants). The reason why group was selected as a factor lies in its role as a cohort of more or less like-minded people, who feel intimate to each other, thus they feel free to discuss in a relaxed way, something which may lead to accommodation of speech (Bell 2001) among its members; the existence of this accommodation renders group a unit of analysis, as it secures a relative homogeneity in the group's stylistic patterns.

Such a choice of factor also resonates with Levon (2009: 51 ), who talks about the supra-local level (similar to the notion of groups in the current study), and proves that such a categorization provides 'insights into how people assemble themselves into ethnographically meaningful groups that are located within a larger socio-political landscape' (ibid.). Levon uses political alignment as an independent factor shared within his groups. In this study, the independent factor shared within the groups is their tight friendship bonds.

\subsection{Topic of Discussion}

I decided to focus on five such topics, and to provide the participants with them in the form of an ethnographically informed agenda, or a 'compass' for

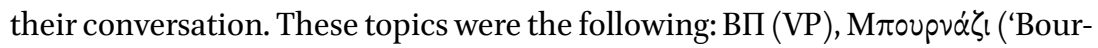

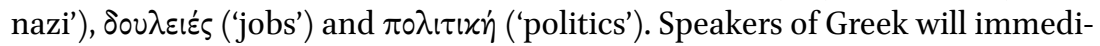
ately notice that these words are very mundane and informal (e.g., the choice

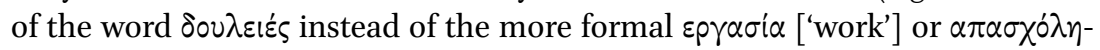
on ['occupation']); the reason for this choice had to do with my effort to leave space for the participants to have an everyday conversation, in which mundane words are used, as opposed to more formal (and thus, less spontaneous) conversations. It should be emphasized that it was not always easy to decide to which topic a specific token could be considered to belong, not only due to the fluidity of the discussions, which resulted in a continuous shifting of the topics, but also due to the numerous moments when participants were introducing new topics, i.e. topics that fell outside the agenda. The tokens belonging to these 'irrelevant' topics, labeled 'other', were also included in the analysis, simply because they were too many to be excluded. 


\subsection{Stance towards the VP-DP Rivalry}

The stance towards the VP-DP rivalry has also been used as a factor. This term includes primarily affective stance, namely the representation of the emotional state of the speaker, whereby individuals can 'lay claims to particular identities and statuses as well as evaluate others' claims and statuses' (Jaffe 20ogb: 7). In this particular case, affective stance is identified with the participants' emotional state towards the VP and the DP cultures, the people associated with them, as well as the practices and ideologies underpinning these two labels. The reason for the incorporation of stance as an interactional factor lies not only in the impossibility of speakers' attendance to the topic until interactional stances have been taken (Scollon 1998: 71-75); rather, it lies in the more nuanced picture it can offer (see articles in Jaffe 2009a and in Englebretson 2007) with respect to the actual relationship between the cultures themselves and the ways people craft their speech, in order to position themselves towards this relationship. More specifically, four types of stance have been identified: Pro VP, anti VP, pro DP, and anti DP. As with the discussion topics, it was not always clear which token fell under which of these stances, because people did not always seem to have a clear view on where they were standing with respect to this issue: for example, there were many instances in which people were trying to sound as neutral towards the VP and DP discourse relationship as possible, both in terms of how they spoke as well as in the content of their speech. In these cases, I made the decision to exclude people's relevant tokens from the analysis.

\section{Data Analysis}

\subsection{Descriptive Statistics}

The guiding questions of the article are the following: to what extent is $\mathrm{V}+/-\mathrm{PP}$ variation a sociolinguistic variable in suburban Athens? What is its distribution and the social meaning thereof?

In light of these questions, the basic hypotheses tested are a) that the Peristeriotes use the nonstandard variants - $\mathrm{PP}$ in their semi-structured conversations more than the VP participants, and b) that the VP participants use the standard variants more than the Peristeriotes (cf. Finegan and Biber 2001: 242).

Regarding the distribution of the factors constraining sociolinguistic variation and its social meaning, my hypothesis is that the distribution is identical for both group of participants with social factors, such as education and area of residence, figuring at the top of the constraining hierarchy. The reason for this is that the nonstandard variant V-PP tends to be associated with careless speech, which in turn usually indexes lack of education (Machlin 1992: 119). 
Table 1. Descriptive statistics for the use of the variable $(\mathrm{N})$

\begin{tabular}{lllr}
\hline PARTICIPANT CATEGORY & V+PP N & V-PP N & TOTAL N \\
\hline VP & 2,518 & 1,979 & 4,497 \\
PERISTERIOTES & 2,396 & 3,448 & 5,844 \\
Total N & 4,914 & 5,427 & 10,341 \\
\hline
\end{tabular}

Significance $=0.06(\mathrm{p}<0.5)$

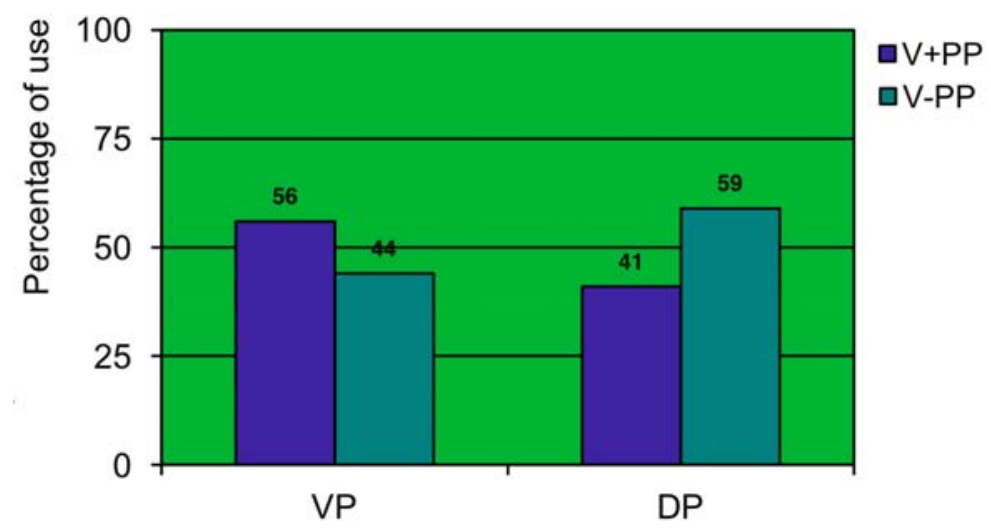

Figure 1. Descriptive statistics for the use of the variable (percentage)

The first observation to be made is the striking difference between the VP participants and the Peristeriotes in terms of their use of the standard and nonstandard variants. Overall, the VP participants have $56 \%$ use of the standard $\mathrm{V}+\mathrm{PP}$, compared to only $41 \%$ among the Peristeriotes, a statistically significant difference $($ chi square $=34.062, p<0.5)$. As both sets of speakers are Athenians belonging to the same age range, this seems to suggest that these are areal differences. The VP participants tend to use more standard features generally, perhaps an indication of their need to index their abiding by the norms of the language, translated into their wish to sound educated and cultivated. On the other hand, the Peristeriotes use the nonstandard variant $59 \%$ of the cases, which is more than the use of the standard variant on behalf of the VP participants. A comparison like this suggests that the Peristeriotes can be seen as more enthusiastic users of nonstandardness in their speech than VP participants as users of standardness, maybe because the former want to create an in-group membership identity, characterized by their preference for (linguistic) features which deviate from the norms established by VP people.

This descriptive statistic analysis paves the way for the variationist analysis of the variable, which aims at unravelling its distribution. The analysis was made 
in two steps: in the first one, all of the tokens from both areas were included in the Varbrul analysis, while in the second one the tokens from each area separately were included. The reason behind this second step was to flesh out what the social meaning of the general factor 'area' is, which was found not only to be statistically significant but also as the strongest factor constraining sociolinguistic variation.

\subsection{Varbul Results}

\section{Macro Level}

The basic hypothesis tested was that the nonstandard variant V-PP is associated with the factor values oriented towards the $\mathrm{DP}$, while the standard variant $\mathrm{V}+\mathrm{PP}$ is associated with the factor values associated oriented towards the VP.

Table 2. Statistically significant macro factors contributing to the use of V-PP in Athenian suburban speech

\begin{tabular}{|c|c|c|c|}
\hline Factor groups & Factors & $\begin{array}{l}\text { Factor } \\
\text { weights }\end{array}$ & $\mathbf{N}$ \\
\hline \multicolumn{4}{|l|}{ Area } \\
\hline & DP & 0.82 & 3,459 \\
\hline & VP & 0.48 & 1,968 \\
\hline & Range & 34 & \\
\hline \multicolumn{4}{|l|}{ Sex } \\
\hline & Male & $0.5^{1}$ & 2,812 \\
\hline & Female & 0.41 & 2,615 \\
\hline & Range & 10 & \\
\hline
\end{tabular}

Log likelihood: $-89 \cdot 357$

Significance $=0.023(\mathrm{p}<0.5)$

Factors not selected as significant: education level, type of education, topic, stance

The macro factor groups that are statistically significant at the level of $\mathrm{p}<0.5$ for the use of the variant $-P P$ on behalf of all groups of speakers belonging to both areas are the following (according to the strength of constraint hierarchy): the area and the sex of the speakers.

Table 2 suggests that the area has been found to be the strongest factor constraining sociolinguistic variation; more specifically, the Peristeriotes tend to very strongly favour (the factor weight is 0.82 ) the use of the nonstandard variant V-PP, while the VP participants disfavour it (the factor weight is 0.48 ). Nonetheless, this disfavouring is not as extreme (i.e. the range is 34 ) as one would have expected on the basis of the negative comments that the use of the V-PP variant triggers. Along the same lines of a not-so-striking difference in the use of the variant, table 2 shows that in the second statistically significant 
factor constraining variation, namely the sex of the speakers, the pattern seems to be in accordance with the previous one: men have been found to only very slightly (the factor weight 0.51 is just above the neutral weight of 0.50 ) favour the nonstandard variant compared to women. In other words, the expected socially diagnostic patterning can be observed: men and less educated speakers favour the nonstandard form (cf. Labov (1990: 210), Fasold (1990: 92) and Tagliamonte (2001: 48), who have found a similar pattern in various English dialects).

Such an analysis at the macro level is a useful point of departure, because it shows that the area, which is the basic label people tend to employ, whenever they discuss the relationship between these two cultures and the people belonging to them, is the strongest factor which constrains sociolinguistic variation in a statistically significant way. But what does this label mean sociolinguistically? What are its dimensions and how do the latter have an impact on the variable grammars used by the participants who live in these two areas? In order to provide answers to these questions, I ran two Varbrul analyses at the micro level, one for each area separately. The findings of these analyses are found immediately below.

\section{Micro Level}

Table 3. Statistically significant factors contributing to the Peristeriotes' use of V-PP in Athenian suburban speech

\begin{tabular}{lllr}
\hline \multirow{2}{*}{ Factor groups } & Factors & $\begin{array}{l}\text { Factor } \\
\text { weights }\end{array}$ & \multicolumn{1}{l}{ N } \\
\hline Stance towards rivalry & & & \\
& Pro DP & 0.82 & 1,302 \\
& Anti VP & 0.73 & 1,245 \\
& Pro VP & 0.49 & 642 \\
& Anti DP & 0.42 & 259 \\
& Range & 40 & \\
Topic & Politics & 0.67 & 1,285 \\
& Jobs & 0.60 & 1,190 \\
& Bournazi & 0.51 & 529 \\
& Other & 0.34 & 286 \\
& VP & 0.32 & 158 \\
& Range & 35 & \\
Type of education & & & \\
& State & 0.80 & 2,610 \\
& Private & 0.46 & 838 \\
& Range & 34 &
\end{tabular}




\begin{tabular}{llll}
\hline Factor groups & Factors & $\begin{array}{l}\text { Factor } \\
\text { weights }\end{array}$ & N \\
\hline Level of education & & & \\
& Secondary & 0.73 & 2,295 \\
& Tertiary & 0.44 & 1,153 \\
& Range & 29 & \\
\hline
\end{tabular}

Log likelihood: -88.420

Significance $=0.000(\mathrm{p}<0.5)$

Factors not selected as significant: Group, sex.

The factor groups that have been found statistically significant at the level of $\mathrm{p}<0.5$ for the use of the variant $-P P$ on behalf of the Peristeriotes are the following (according to the strength of constraint hierarchy): the interactional factor groups of stance towards the VP-DP rivalry and the topic of discussion as well as the social factors of type of education and level of education.

With respect to the most significant factor group, namely the stance towards the VP-DP rivalry, table 3 shows that both pro DP and anti VP stance highly prefer the nonstandard variant V-PP, while pro VP and anti DP seem to disfavour the nonstandard variant (although, not significantly less than the neutral point of 0.5). A result like this suggests that when the Peristeriotes discuss and position themselves in favour of the DP culture or against the VP one, they seem to prefer the use of the nonstandard variant, a fact which points towards their identifying the social meaning of speaking in favour of their own area and culture with the social meaning of speaking against their 'sociocultural rival', namely the area and the culture of the VP.

Similarly, but with not such a striking difference, the factor group of topic has been found to be the second most significant factor constraining the Peristeriotes' variable grammar. More specifically, topics like politics and jobs, which in the lives of the Peristeriotes hold a major position, have been found to favour the use of the nonstandard variant (not as extremely as one would have expected, though), while topics like VP and others, that do not fall under the agenda the participants were asked to discuss, seem to favour the use of the standard variant. Given its factor weight very close to the 0.50 threshold (0.51), Bournazi does not significantly constrain the use of the nonstandard variant. Trying to interpret this pattern, I would suggest that through their sociolinguistic behaviour preferring the nonstandard variant, the Peristeriotes are trying to make a statement regarding their political, professional and social profile; both of these topics share the fact that they are associated with emotions. More specifically, regarding politics and jobs, even though the semi-structured conversations were recorded before the major financial crisis which broke out in Greece in 2009, the Peristeriotes in particular tended to express very negative 
emotions and stances towards their personal job status and the political scene of Greece at the time of the recording (see also Theodoropoulou 2012). Therefore, so far the analysis seems to suggest that the speakers' stance towards their own and against the rival area as well as towards significant topics associated with the participants' everyday life favour the use of the nonstandard variant V-PP. Trying to decipher the social meaning of such a pattern I would suggest that they are trying to construct whatever has to do with their area, culture and life (and whatever runs contrary to these) as nonstandard, in order to index their coolness, their peculiarity as a community and, eventually, their deviation from the VP area and culture, which in turn is associated with 'standard' lifestyle and sociolinguistic choices. The former translate into the idea that everyone is trying to imitate these lifestyle models, which include the buying of a spacious property, be it a flat or a house, or the ability to spend money, in order to enjoy a luxurious life. The latter include the use of standard linguistic features.

Table 3 shows that the third and the fourth most significant factor groups are the type of education and the level of education, respectively. More specifically, the Peristeriotes who have graduated from state schools and the ones who have graduated from high school (but do not hold any university diplomas) favour very strongly the use of the nonstandard variant V-PP, contrary to the ones who have graduated from private schools and the ones who have university diplomas. Please note that these two groups do not coincide, i.e. the ones who have graduated from private schools are not necessary the ones who have university degrees. On the basis of this finding, there is evidence that the pattern shared by these two types of social factors is that both graduation from a state school and the status of not having a university degree favour the nonstandard variant, while both graduation from a private school and the possession of a university degree do not favour the use of the nonstandard variant. This observation lends sociolinguistic support to the stereotypification of private schools and tertiary level education as vital aspects of the lifestyle associated with the VP area. This means that people who identify themselves with the DP area and its respective lifestyle will try to keep their distance from the VP area, not only in terms of their frowning upon the VP lifestyle, but also and most importantly by employing nonstandard speech, through which they index this distance.

To summarize, Table 3 has provided us with the interactional and social factors which have been found to be statistically significant in the variable grammar of the Peristeriotes. The stance towards the VP-DP rivalry, the topic of discussion, the type and level of education are these dimensions, which give the label 'DP' its social meaning in sociolinguistic variation; more specifically, it has been found that pro-DP and anti VP stance coupled with discussion of topics, like politics and jobs, which are of paramount importance for the Peristeriotes, both favour the use of the nonstandard variant. In addition, the social factors 
of type and level of education, strongly associated with the aforementioned interactional factors at the level of DP identity construction, also show a strong preference for the use of the nonstandard variant V-PP.

Table 4. Statistically significant factors contributing to the VP participants' use of V-PP in Athenian suburban speech

\begin{tabular}{lllr}
\hline Factor groups & Factors & $\begin{array}{l}\text { Factor } \\
\text { weights }\end{array}$ & N \\
\hline Group of speakers & G3 'non hard core VPs' & o.90 & 780 \\
& G4 'cool VPs' & 0.67 & 649 \\
& G1 'ideal VPs' & 0.31 & 346 \\
& G2 'serious VPs' & 0.30 & 204 \\
& Range & 60 & \\
Stance towards rivalry & & & \\
& Anti DP & 0.91 & 735 \\
& Anti VP & 0.83 & 704 \\
& Pro DP & 0.39 & 398 \\
& Pro VP & 0.35 & 142 \\
& Range & 56 & \\
& & & \\
Topic & Politics & 0.68 & 836 \\
& Jobs & 0.59 & 790 \\
& Bournazi & 0.50 & 161 \\
& Other & 0.47 & 128 \\
& VP & 0.31 & 64 \\
& Range & 37 & \\
\hline
\end{tabular}

Log likelihood: -90.142

Significance $=0.019(\mathrm{p}<0.5)$

Factors not found significant: stance towards the VP-DP rivalry, sex, type of education, level of education.

The factor groups that have been found statistically significant at the level of $\mathrm{p}<0.5$ for the use of the variant -PP on behalf of the VP participants are the following (according to the strength of constraint hierarchy): group of speakers, stance towards the VP-DP rivalry, and topic of discussion. The strongest factor constraining variation in VP participants is the group of speakers. More specifically, group 3, itself self-categorized as 'non-hard core VP', consists of three VP men of mixed academic backgrounds who enjoy hanging out in Exarhia square, one of the 'alternative' hangouts where a great diversity of people can be found, and they also enjoy playing football. These two common practices render them non-hardcore VP people, in the sense that they hang out in places outside the boundaries of the VP geographical zone, and they also meet with non-VP people: one of the group members because of his inherent sociability and interest in getting to know diverse people, and the other two due to 
their respective jobs (one is a wedding caterer and the other one is a doctor). As a result, this non-hard core VP-ness is reflected in their stylistic behaviour through the strong preference for the nonstandard variant of Verb-PP. Along the same lines, self-identified as group 4, the 'cool VPs', consists of people who hold university degrees; all of them are teachers in state schools in the VP area. My interpretation for the preference of the nonstandard variant, although not as striking as the use thereof on behalf of the previous group, is that it has its origins in the TV series $\mathrm{G}_{4}$, which at the time of the ethnographic study was one of the group members' favourite TV programs. The show's plot revolves around the school life of some teenagers at a state school in the mostly working class DP municipality of Petroupoli. The series contains lots of discussions among these teenagers, where this syntactic pattern is heavily used (again, this is an observation made on an anecdotal basis). If we accept that popular culture both reflects the linguistic situation within a society, and influences people's linguistic behavior (cf. Spitulnik 1993: 294; chapters in Johnson and Ensslin 2007; Danesi 2008: 243-264), it can be argued that teachers come across similar linguistic situation, such as the one reflected in the TV series, and in a way they accommodate to this situation not only when talking to their students but also when talking to each other informally.

Groups 1 and 2, who clearly disprefer the use of the nonstandard variant V-PP, are the ones who self-categorize as ideal and as serious VPs respectively. This dispreference could be seen as their effort to live up to their labels by adopting a linguistic behaviour tailored according to their understanding of $\mathrm{VP}$, which is mainly characterized by their abiding by the norms of standardness.

The second strongest factor has been found to be the stance towards the VP-DP rivalry. Table 4 suggests that there is a striking pattern: antipathy, regardless of whether it is directed towards the DP or the VP area, tends to favour very strongly the use of the nonstandard variant, while support towards the DP or the VP area disfavours the use of the nonstandard, i.e. favours the use of the standard form. My interpretation of this finding is that antipathy can be seen as an emotionally-loaded movement in conversation, which as such makes people more involved in speech and thus it makes them monitoring their speech less; as a result of this, nonstandard features tend to surface and prevail, one of which, in the case of this particular study, is the use of the nonstandard variant V-PP.

The third strongest factor group, which has been found to constrain the VP participants' sociolinguistic variation, is the topic of discussion. Like in the case of the Peristeriotes (see table 3 ), the pattern is identical: politics and jobs seem to prefer the use of the nonstandard variant, as opposed to less emotionally-loaded topics, such as VP and other topics. Of course, one could 
argue that VP, as an area and culture, which is widely stereotypified in popular culture, could trigger emotional reactions (laughter, ironic comments) of behalf of both groups of participants, namely the Peristeriotes and the VP participants alike, expressed in a nonstandard way; however, regarding the specific variable the Varbrul analysis has not shown any evidence for the preference of the nonstandard variant by any of these groups.

To summarize, the Varbrul analysis ran separately for the Peristeri and the VP groups of participants respectively has shown that sociolinguistic variation is constrained by the stance towards the VP-DP rivalry and by the topic of discussion for both groups; nonetheless, for the Peristeriotes it has been found that the type and level of education is part of their variable grammars, while for the VP participants the social factor that has been found to belong to their variable grammar is that of the group of speakers. In the next section, I try to interpret these similarities and differences, to delve into their social meaning, and finally, to discuss their sociolinguistic implications.

\section{Concluding Discussion}

The guiding questions of the article were the following two: 1) to what extent is $\mathrm{V}+/-\mathrm{PP}$ variation a sociolinguistic variable in suburban Athens? And 2) what is its distribution and the social meaning thereof?

Regarding the first one, it has been found that $\mathrm{V}+/-\mathrm{PP}$ is a linguistic variable in suburban Athenian speech, and to be more precise, between VP and Peristeri people, inasmuch as it is two alternative ways of saying the same thing, in this particular case the expression of movement. Nonetheless, it is also a sociolinguistic variable, because its variation is constrained by social and interactional factors, as tables 2, 3, and 4 have shown. With respect to its use, table 1 lends support to the verification of the two hypotheses tested, namely that the Peristeriotes use the nonstandard variant-PP in their semi-structured conversations more than the VP participants, and b) that the VP participants use the standard variant more than the Peristeriotes.

Regarding the more interesting question of the distribution of the factors constraining sociolinguistic variation, the hypothesis that the distribution is identical for both groups of participants with social factors, such as education and area of residence, figuring at the top of the constraining hierarchy has been partly verified.

On the one hand, the common denominator in both VP participants and Peristeriotes' variable grammar is that both the stance towards the VP-DP rivalry and the topic of discussion have a similar constraint ranking, meaning that in both cases stance is stronger than the topic of discussion. Tables 3 and 4 show that antipathy is a stance, which favours very strongly the use of the 
nonstandard variant in both groups. In addition, Peristeriotes' support and love for their own area and the sociocultural package that goes with it are also expressed through the nonstandard variant. In light of this, I argue that the sociolinguistic variable $\mathrm{V}+/-\mathrm{PP}$ is mobilized to do relational work, and this ties in with the analytical need to treat sociolinguistic variables in a more contextbased and thus more dynamic way. What this suggests is that this ephemerality of stance and topic renders people flexible when it comes to issues of (social class) identity negotiations, and it is rather this fleetingness that should inform any sociolinguistic variation analysis. This interactional variation can be fleshed out in a more transparent way through data from (semi-structured) conversations rather than sociolinguistic interviews. The reason for this is that in the latter the interviewer is heavily biased in favour of being a receptive listener rather than an equal partner (Gregersen and Pedersen 1991: 54), whereas the chances of having this state of affairs are significantly reduced in a conversation between friends, where there is usually equality and mutual engagement.

On the other hand, education has been found statistically significant only in the micro level analyses of the two areas separately, and to be more accurate, only in the Peristeriotes case. A finding like this suggests that only for the Peristeriotes do their type and level of education constrain their variable grammar, thus rendering them more social class-wise sensitized towards the use of the variable, since education is arguably a vital dimension of people's social class positioning and orientation. The corresponding social factor that has been found to constrain the VP participants' variable grammar is their group, according to table 4, a fact that lends support to the idea that VP people are more influenced by their friendship groups rather than their actual social class. Trying to tackle the thorny issue of theorizing the relationship between social networks and social class, my findings point towards the idea that groups of people, who stem from leafy areas (and thus belonging to well off social classes, as I have shown in Section 2 of this paper) but orient themselves towards practices not so social class-relevant, tend to favour the nonstandard variant. This runs contrary to Milroy and Milroy's (1992: 17) observation that upper classes comprise of strong networks, which as such are dense and multiplex and, as a result of this, prefer standard speech. My data suggest that it is practices which influence the physiognomy of a group of people, who in turn opt for being flexible in terms of using the standard or the nonstandard variant depending on interactional factors, such as stance or topic of discussion. In general, what this suggests for the relationship between social class and social network is that we need to tease out the sub-groupings emerging within social classes in a contextualized way, and groups of people formed on the basis of 
friendship ties could be seen as a useful vector along which sociolinguistic variation is structured and stratified (cf. Cheshire et al. (2008), who have argued that friendship networks contribute towards language change, i.e. linguistic innovation).

Overall, it needs to be stressed that the findings from the Varbrul analysis are generalizable in similar samples of speech and similar corpora, i.e. in data collected from similar types of participants through a similar methodology; they are not generalizable across the whole population of the northern and western suburbs of Athens.

In sum, social factors, like education, group and sex differences along with interactional factors, like stance and topic of discussion are heavily implicated in the variation between $\mathrm{V}+\mathrm{PP}$ and V-PP in suburban Athenian speech. Thus, we could argue that this variation seems to be used by Athenian suburbanites as a sociolinguistic marker in their conversations. Nonetheless, in order to make sweeping claims about the status of this variable in Athenian speech, we need more variationist sociolinguistic studies from other areas of suburban and downtown Athens.

\section{Acknowledgements}

This study has been funded by the Greek State Scholarships Foundation (IKY), the Alexander S. Onassis Public Benefit Foundation ( $\Omega v \alpha \dot{\alpha} \sigma ı)$, and the Foundation for Education and European Culture (ІПЕП). To these institutions I remain indebted. In addition, thanks go to the audiences in ICLaVE 5 and ICGL 10, where versions of this material were presented. Finally, I am grateful to Devyani Sharma and the two anonymous reviewers for useful feedback on earlier drafts of this paper. Any remaining oversights are solely mine.

\section{References}

Aguilar-Sánchez, Jorge. 2009. How Many Speakers? How Many Tokens?: A Methodological Contribution to the Study of Variation. Paper presented at the New Ways of Analyzing Variation 38 (NWAV 38 ) Conference, 22-25 Oct., University of Ottawa.

Arvaniti, Amalia and Brian Joseph. 20oo. Variation in Voiced Stop Prenasalization in Greek. Glossologia, A Greek Journal for General and Historical Linguistics 11-12: 131-166.

Bell, Allan. 2001. Back in Style: Reworking Audience Design. In Penelope Eckert and John R. Rickford (eds.), Style and Sociolinguistic Variation. 139-169. Cambridge: Cambridge University Press.

Cairns, Barbara. 1991. Spatial Deixis: The Use of Spatial Co-ordinates in Spoken Language. Lund University Department of Linguistics Working Papers 38: 19-28. Available inwww.sciecom.org/ ojs/index.php/LWPL/article/view/2568/2143 (9/10/2011).

Canakis, Costas. 2007. Isagogi sti Pragmatologia: Gnostikes kai Kinonikes Opseis tis Glossikis Hrisis. [Introduction to Pragmatics: Cognitive and Social Aspects of Language Use]. Athens: Ekdoseis tou Eikostou Protou. 
Cheshire, Jenny. 2002. Sex and gender in variationist research. In Jack K. Chambers, Peter Trudgill and Natalie Schilling-Estes (eds.), Handbook of Language Variation and Change. 423-443. Oxford: Blackwell.

Cheshire, Jenny and Sue Fox. 2009. Was/were variation: A perspective from London. Language Variation and Change 21: 1-23.

Cheshire, Jenny, Sue Fox, Paul Kerswill, and Eivind Torgersen. 2008. Ethnicity, friendship network and social practices as the motor of dialect change: linguistic innovation in London. Sociolinguistica 22: 1-23.

Danesi, Marcel. 2008. Popular Culture. Introductory Perspectives. Lanham, MD/Plymouth, UK: Rowman and Littlefield.

Emmanuel, Dimitris. 2004. Socio-economic inequalities and housing in Athens: Impacts of the monetary revolution of the 1990s. The Greek Review of Social Research 113, 121-143.

Emmanuel, Dimitris. 2007. Kinoniki dieresi tou horou kai kinonikos diahorismos stin Athina: o rolos tis ikonomikis taxis, tou status kai tis katikias. [Social division of space and social distribution in Athens: The role of financial class, status and residence]. Report of the Research Program 'Tendencies of Social Reformation in Urban Space: Social Reproduction, Social Inequalities and Social Cohesion in 21st century Athens'. Athens: National Center for Social Research (EKKE).

Emmanuel, Dimitris. 2008. Kinonikos diahorismos, polosi ke anisotites sti geografia tis Athinas: o rolos ton mihanismon tis agoras katikias kai ikistikis anaptyxis (1980-200o). [Social segregation, polarization and inequalities in the geography of Athens: the role of the mechanisms of real estate and urban development (1980-200o)]. Geografies 3: 46-70.

Englebretson, Robert (ed.). 2007. Stancetaking in Discourse. Amsterdam: Benjamins.

Fasold, Ralph. 1990. The Sociolinguistics of Language. Introduction to Sociolinguistics. Volume II. Malden, MA/Oxford: Blackwell.

Finegan, Edward and Douglas Biber. 2001. Register variation and social dialect variation: The register axiom. In Penelope Eckert and John R. Rickford (eds.), Style and Sociolinguistic Variation. 235-267. Cambridge: Cambridge University Press.

Gregersen, Frans and Inge Lise Pedersen (eds.). 1991. The Copenhagen Study in Urban Sociolinguistics. Copenhagen: C.A. Reitzels Forlag.

Jaffe, Alexandra (ed.). 20oga. Stance. Sociolinguistic Perspectives. Oxford: Oxford University Press. Jaffe, Alexandra. 20ogb. Introduction. In Alexandra Jaffe (ed.), Stance. Sociolinguistic Perspectives. $3^{-28}$. Oxford: Oxford University Press.

Johnson, Sally and Astrid Ensslin (eds.). 2007. Language in the Media. New York: Continuum.

Joseph, Brian D., and Irene Philippaki-Warburton. 1987. Modern Greek. London: Croom Helm.

Labov, William. 2006. The Social Stratification of English in New York. Second Edition. Cambridge: Cambridge University Press.

Labov, William. 1990. The intersection of sex and social class in the course of linguistic change. Language Variation and Change 2: 205-254.

Labov, William. 1971. The study of /language in its social context. In Joshua A. Fishman (ed.), Advances in the Sociology of Language Vol. 1. 152-216. The Hague: Mouton.

Levon, Erez. 2009. Dimensions of style: context, politics and motivation in gay Israeli speech. Journal of Sociolinguistics 13: 29-58.

Machlin, Evangelin. 1992. Speech for the Stage. New York: Routledge/Theatre Arts Books.

Macy, Michael W. 2001. Social class. In: Mesthrie, Rajend (ed.), Concise Encyclopedia of Sociolinguistics. 362-369. Oxford: Elsevier.

Maloutas, Thomas. 2002. Kinonikos kai Ikonomikos Atlas tis Elladas-Oi Poleis [Social and Economic Atlas of Greece-The Cities]. Athens: National Centre for Social Research (EKKE) and Thessaly University Press.

Maloutas, Thomas and Nikos Karadimitriou. 2001. Vertical social differentiation in Athens: Alternative or complement to community segregation? International Journal of Urban and Regional Research 25(4): 699-716. 
Meyerhoff, Miriam. 2011. Introducing Sociolinguistics. Second Edition. New York: Routledge.

Mikros, Georgios K. 1997. Koinioglossologiki Proseggisi Fonologikon Provlimatos tis Neas Ellnikis. Fonitiki Pikilia ton Errinon Simfonon. [A Sociolinguistic Approach of Phonological Problems in Modern Greek. Phonetic Variety of Nasal Consonants]. Ph.D. Dissertation, University of Athens.

Milroy, Lesley and Milroy, James. 1997. Varieties and variation. In Florian Coulmas (ed.), The Handbook of Sociolinguistics. 47-64. Oxford: Blackwell.

Milroy, Lesley and Milroy, James. 1992. Social network and social class: Toward an integrated sociolinguistic model. Language in Society 21: 1-26.

Psaltou-Joycey, Angeliki and Marina Valiouli. 1995. Pame platia? Chrisi i apousia tou emprothetou arthrou. [Shall we go square? Use or absence of the Prepositional Phrase]. Studies in Greek Linguistics. Festschrift for Prof. M. Setatos. Proceedings of the 15th Annual Meeting of the Department of Linguistics. 292-303. Thessaloniki: School of Philology, Aristotle University of Thessaloniki.

Scollon, Ron. 1998. Mediated Discourse as Social Interaction: A Study of News Discourse. Reading, MA: Addison-Wesley.

Sørensen, Aage. 2001. A Ricardian approach to class analysis. In: Erik O. Wright (ed.), Alternative Foundations of Class Analysis. 130-178. URL http://www.ssc.wisc.edu/ wright/Found-all .pdf (16/4/2013)

Spitulnik, Debra. 1993. Anthropology and mass media. Annual Review of Anthropology 22: 293-315. Tagliamonte, Sali. 2011. Variationist Sociolinguistics: Change, Observation, Interpretation. New York: Wiley-Blackwell.

Tagliamonte, Sali. 2006. Analyzing Sociolinguistic Variation. Cambridge: Cambridge University Press.

Tagliamonte, Sali. 2001. Come/came variation in English dialects. American Speech 76(1): 42-61.

Theodoropoulou, Irene. 2012. Sociolinguistic profile of the Generation of 700 Euros. In: Frangaki, Georgia, Thanassis Georgakopoulos and Charalambos Themistocleous (eds.), Current Trends in Greek Linguistics. 177-196. Newcastle: Cambridge Scholars Publishing.

Theodoropoulou, Irene. 2011. Popular literature discourses of Athenian suburbia: Northern suburbs. Articulo-Journal of Urban Research. Special Issue 3 (2010): Revisiting Urbanity and Rurality. http://articulo.revues.org/1582 (16/4/2013)

Theodoropoulou, Irene. 2010a. A stylistic perspective on Athenian suburbia as a culture of conflicting social constructities. In Sibylle Baumbach (ed.), Regions of Culture-Regions of Identity. 151-174. Trier: Wissenschaftlicher Verlag Trier.

Theodoropoulou, Irene. 2010b. Authentication of the Athenian 'new-rich' and 'new-poor' suburbanite identities. In Emilia Parpală and Carmen Popescu (eds.), Comunicare, Identitate, Cultură [Communication, Identity, Culture]. 219-232. Craiova: Editura Universitaria.

Theodoropoulou, Irene. 2010c. Indexicalities of Modern Greek speech style: A comparative sociolinguistic study on Athenian suburban class identities. Ph.D. Dissertation, King's College London, UK.

Triantafyllopoulou, Anastasia. 2006. Peristeri-IExelixi tis Polis, IDomi kai o Rolos tis Topikis Aftodiikisis. [Peristeri-The Development of the City, the Structure and the Role of its Local Government]. Athens: Vivliorama.

Wolfram, Walt. 1993. Identifying and interpreting variables. In Dennis R. Preston (ed.), American Dialect Research. 193-221. Amsterdam:John Benjamins. (Reprinted in Michael Inn (ed.), Dialect and Language Variation. Academic Press, 1999.) 